\title{
BN AND Si-DOPED BN COATINGS ON WOVEN FABRICS
}

\author{
Frances I. Hurwitz \\ NASA Glenn Research Center \\ Cleveland, $\mathrm{OH} 44135$ \\ John M. Scott \\ Refractory Composites, Inc. \\ Glen Burnie, MD 21060
}

\author{
Paul V. Chayka \\ MS\&E Resources \\ New Milford, CT 06776 \\ Donald R. Wheeler \\ SEST, Inc. \\ Cleveland, OH 44135
}

\begin{abstract}
A computer controlled, pulsed chemical vapor infiltration (CVI) system has been developed to deposit $\mathrm{BN}$ from a liquid borazine $\left(\mathrm{B}_{3} \mathrm{~N}_{3} \mathrm{H}_{6}\right)$ source, as well as silicon doped $\mathrm{BN}$ coatings using borazine and a silicon source, into $2-\mathrm{D}$ woven ceramic fabric preforms. The coating process was evaluated as a function of deposition temperature, pressure, and precursor flow rate. Coatings were characterized by field emission scanning electron microscopy, electron dispersive spectroscopy and Auger spectroscopy. By controlling the reactant feed ratios, $\mathrm{Si}$ incorporation could be controlled over the range of 6-24 atomic percent.
\end{abstract}

\section{INTRODUCTION}

Boron nitride provides a mechanically weak interphase which promotes debonding in ceramic matrix composites. It is, however, susceptible to oxidation, especially in moist environments [1-3] at intermediate temperatures $\left(600-1000^{\circ} \mathrm{C}\right)[4,5]$, forming a glass which leads to composite embrittlement. Improvement in BN stability can be attained by high temperature deposition $\left(1400-1800^{\circ} \mathrm{C}\right)$, which increases BN crystallinity [6], or by incorporation of a Si dopant at $1400^{\circ} \mathrm{C}[4,6]$. However, CVI deposition at this high a temperature leads to thick surface coatings without infiltration into the fabric weave, or into the interior of a perform. Improved moisture resistance $[7,8]$ relative to $\mathrm{BN}$ also has been demonstrated for $\mathrm{SiBN}$ ternary films deposited at low temperatures $\left(300-500^{\circ} \mathrm{C}\right)$; these coatings have found application in the electronics industry, but have not been used in structural ceramic matrix composites.

The present study uses a pulsed flow CVI process to develop a coating system suitable for infiltration of Sylramic woven cloth and stacked cloth performs. Borazine $\left(\mathrm{B}_{3} \mathrm{~N}_{3} \mathrm{H}_{6}\right)$ was used as the BN precursor, and dichlorosilane (DCS) provided the Si source. Coatings were deposited over a temperature range of $600-1000^{\circ} \mathrm{C}$. Pressure and precursor flow rates also were varied.

\section{EXPERIMENTAL}

The liquid delivery system and CVI reactor design used for coating deposition have been described in detail elsewhere[9]. For initial screening studies here, a smaller reactor with a $5 \mathrm{~cm}$ I.D. and $30 \mathrm{~cm}$ hot zone were used to minimize oxygen incorporation in the coating resulting from vacuum leaks in the larger reactor, and to conserve borazine. A diffuser plate also was added to improve the uniformity of coating deposition. Borazine was synthesized by Boron 
Technologies (Fancy Gap, VA). The substrate was a Sylramic SiC (Dow Corning) 5 HS cloth woven at 7.8 ends per cm. Fabric samples were $5 \times 25 \mathrm{~cm}$ or $2.5 \times 25 \mathrm{~cm}$. Preforms were formed by stacking eight plies of cloth, fixtured with drilled graphite tooling.

Two test matrices were used to screen coating parameters. The first studied the effects of deposition temperature and borazine flow rates. Deposition cycles were fixed at 100 pulses. An initial run using a purge gas and pressure of 65 torr was used to ascertain the influence of the diffuser and have comparability with data from a prior study [9]; all subsequent runs were at 25 torr. Coating thickness was determined by field emission scanning electron microscopy (FESEM) and by Auger depth profiling. Based on this matrix, a deposition temperature was selected, and a second matrix used to investigate parameters for incorporation of Si dopant. In the second matrix, deposition temperatures were limited to 800 and $1000^{\circ} \mathrm{C}$. All runs were followed by heat treatment at $1000^{\circ} \mathrm{C}$ for $1 \mathrm{~h}$. Borazine flow was at 0.3 or $0.6 \mathrm{ml} / \mathrm{min}(0.0034$ or $0.0068 \mathrm{mols} / \mathrm{min})$, as was the case in Matrix I. DCS flow was varied from 0.00028 to $0.00224 \mathrm{mols} / \mathrm{min}$. $\mathrm{NH}_{3}$, which had been used in two of the runs in Matrix I, was present for all runs in Matrix II, at three flow rates, ranging from 0.016 to $0.063 \mathrm{mols} / \mathrm{min}$.

On the basis of results from Matrices I and II, four runs were made to evaluate infiltration into small eight ply performs $(5 \mathrm{~cm} \times 7.5 \mathrm{~cm})$ : two with $\mathrm{BN}$ alone and two with Si dopant. Single plies of fabric were included before and after the perform stacks, relative to flow direction, as a control.

\section{RESULTS AND DISCUSSION}

The influence of temperature on coating thickness, based on Matrix I, is summarized in Fig 1. Coating thickness increases with deposition temperature. Ammonia appeared to reduce coating thickness substantially at $800^{\circ} \mathrm{C}$ (In Matrix I, $\mathrm{NH}_{3}$ flow alternated with borazine and $\mathrm{N}_{2}$ purge cycles.) Given the thickness variation from fiber to fiber on various parts of the cloth, and the limited number of data points, it appears that thin coatings could be achieved at either borazine flow rate. The variation in coating thickness is readily observed in FESEM micrographs (Fig. 2). Deposition at $800^{\circ} \mathrm{C}$ (Fig 2 a, c and d) produced fairly uniform coatings, with good fabric handling and flexibility, while that at $1000^{\circ} \mathrm{C}$ resulted in very thick coatings and stiff fabrics. The coating produced at the higher borazine flow rate ( $\mathrm{c}$ and d) was smoother than that at 0.3 $\mathrm{ml} / \mathrm{min}$; the latter exhibited small nodules of $\mathrm{BN}$ on the fiber surface, possibly arising from non-uniformity in the borazine flow.

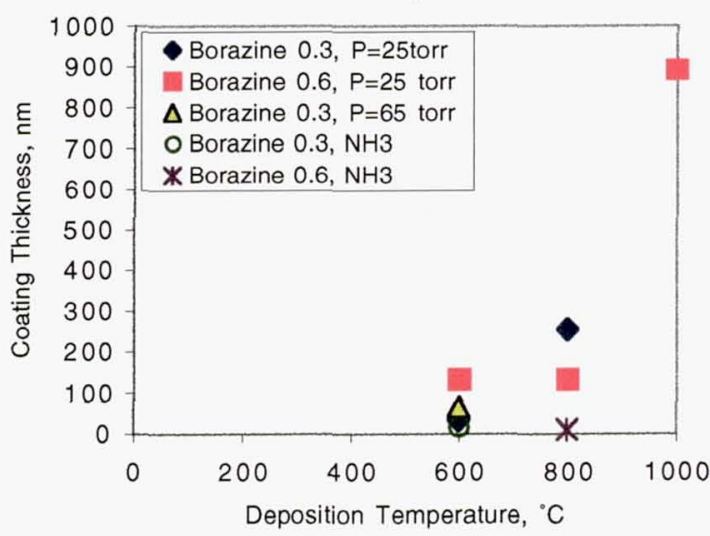

Figure 1. Effect of deposition temperature on coating thickness. 

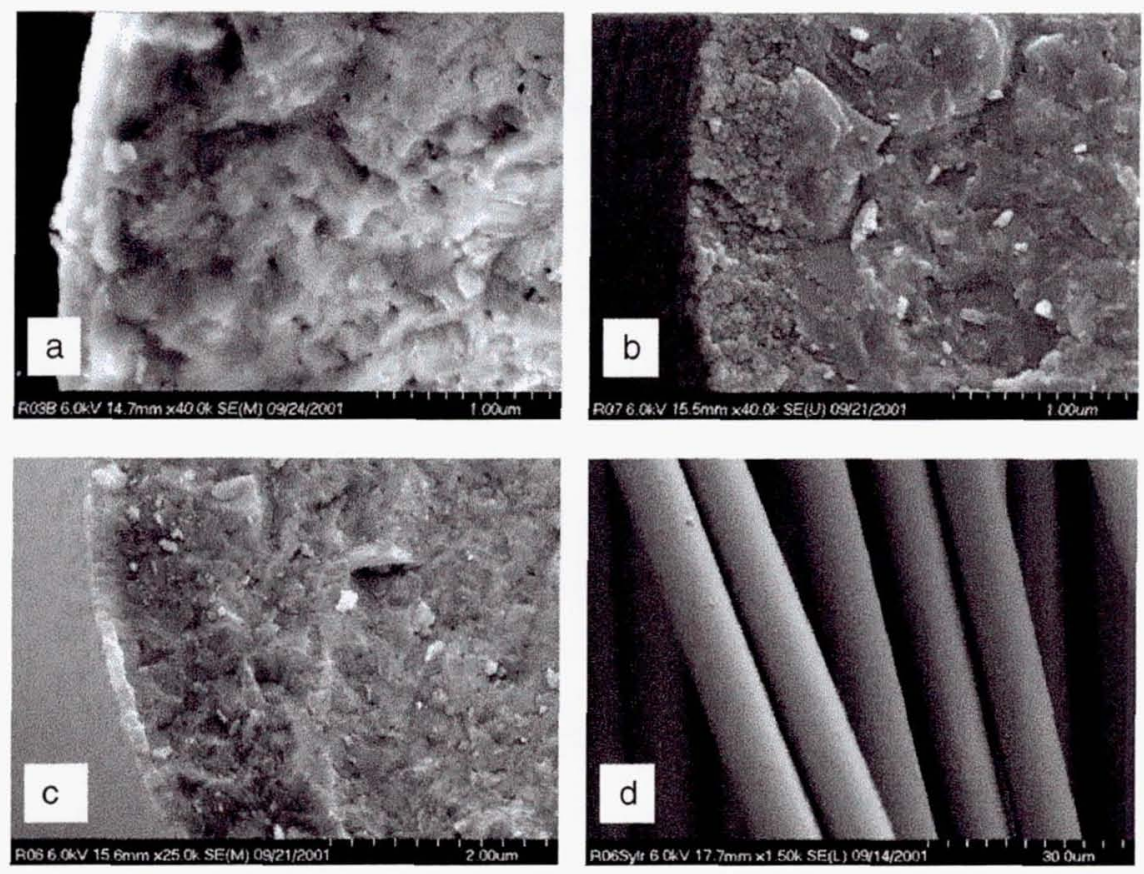

Figure 2. Coatings deposited at $800^{\circ} \mathrm{C}$ (a, c and d), and $1000^{\circ} \mathrm{C}$ (b). Borazine flow was $0.3 \mathrm{ml} / \mathrm{min}$ in (a), $0.6 \mathrm{ml} / \mathrm{min}$ in (b)-(d).

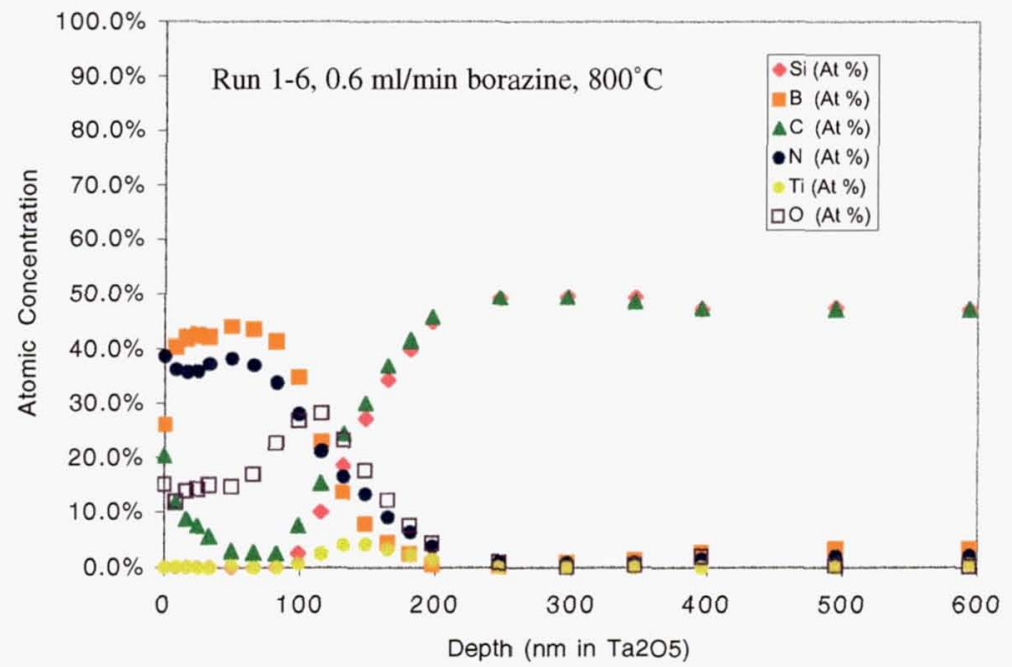

Figure 3. Auger depth profile of fibers from Run $6,0.6 \mathrm{ml} / \mathrm{min}$ borazine, $800^{\circ} \mathrm{C}$ deposition coating. 


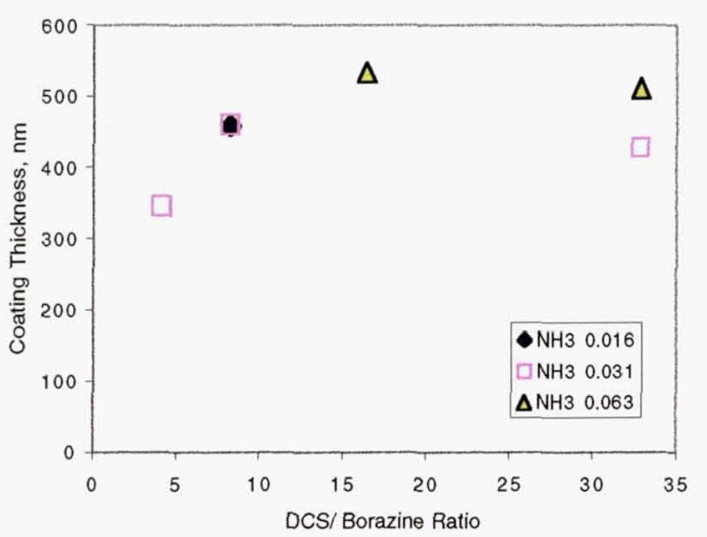

Figure 4. Influence of DCS/ Borazine molar ratio on coating thickness.
Auger depth profiles show $\mathrm{Ti}$ enrichment at the fiber surface for all the $\mathrm{BN}$ coatings. Typically, there also is $\mathrm{C}$ incorporation, as well as $\mathrm{O}$, with some increase in oxygen at the interface. Addition of $\mathrm{NH}_{3}$ during deposition, intended to increase $\mathrm{N}$ incorporation, resulted in coatings which were exceedingly thin $(10 \mathrm{~nm}$ or less). The N/B ratio was substantially less than 1 , probably due to formation of $\mathrm{B}-\mathrm{O}$ species.

Matrix II was designed to establish parameters for incorporating $\mathrm{Si}$ as a dopant. All runs included ammonia as a nitrogen source, and ammonia and borazine flows were concurrent. The $0.6 \mathrm{ml} / \mathrm{min}$ borazine, $800^{\circ} \mathrm{C}$ deposition was selected as a

starting point, as it had produced the most uniform coating with desired thickness in Matrix I. Coating thickness increased substantially with the addition of DCS deposition cycles (Fig. 4, cf. Fig. 1) There was little effect of $\mathrm{NH}_{3}$ flow rate. There was insufficient data to separate main effects and interactions among parameters. Characteristic Si-doped coatings are shown in Fig. 5.
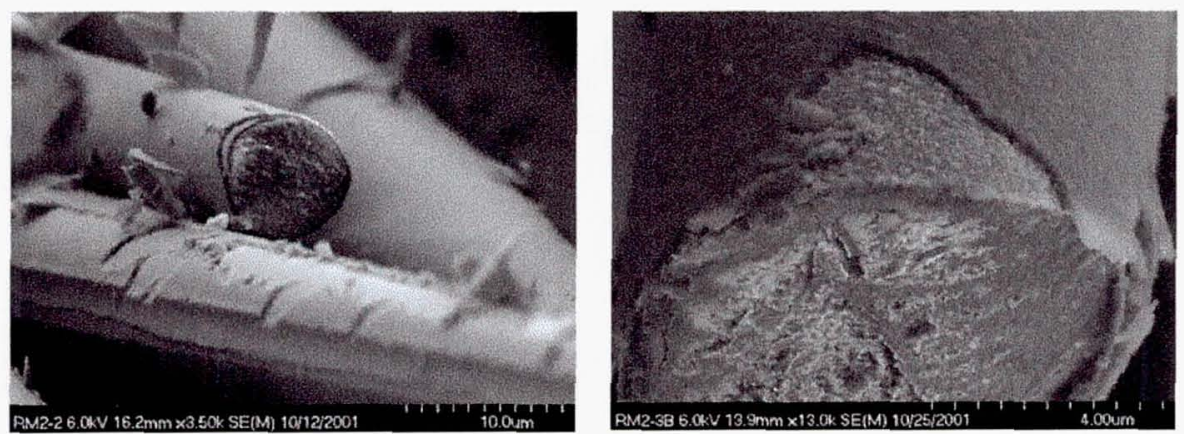

Figure 5. Coating deposited at $0.6 \mathrm{ml} / \mathrm{min}$ borazine, DCS/ Borazine ratio of 32.8 (Run M2-2, left), and $0.3 \mathrm{ml} / \mathrm{min}$ borazine, DCS/ Borazine ratio of 8.2 (Run M2-3B, right).

The DCS/ borazine ratio also had a striking effect on coating chemistry (Figs. 6 and 7), producing Si dopant levels which varied from 6 atomic percent at a DCS/ borazine ratio of 8.2, to 24 atomic percent at a ratio of 32.8 and high borazine $(0.6 \mathrm{~mol} / \mathrm{min})$ flow rate. Si incorporation was about half that, or 13 atomic percent, at the same 32.8 ratio, but at half the borazine flow. An enrichment in $\mathrm{Si}$ at the coating surface (Fig. 6) was seen in several of the coatings. Carbon and oxygen incorporation in the Matrix II coatings was substantially less than that seen in the un- 


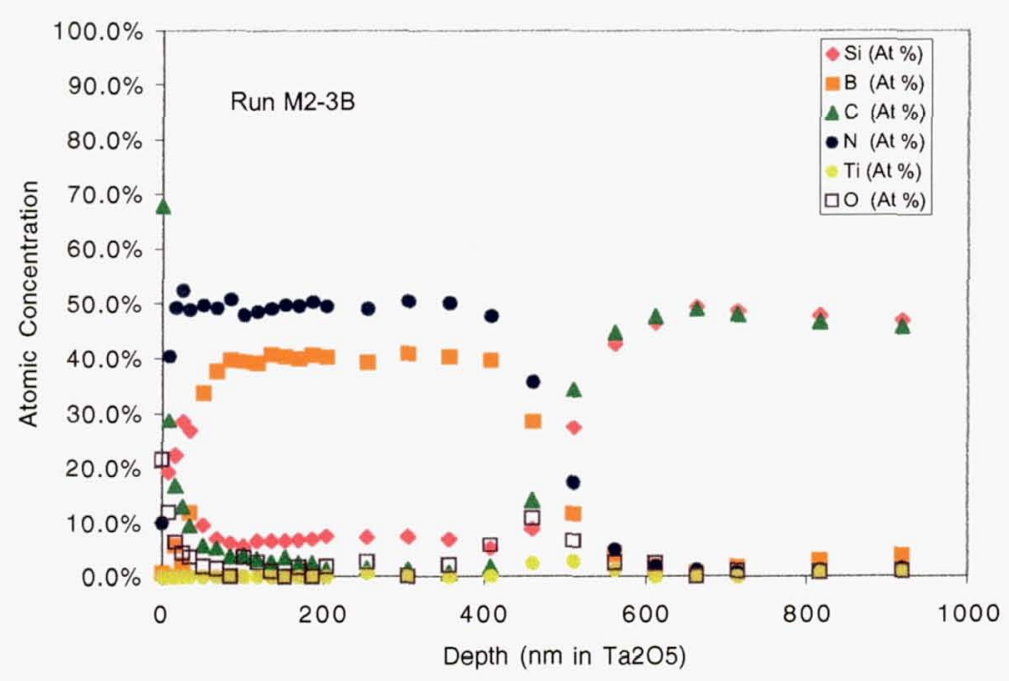

Figure 6. Auger depth profile, coating deposited at borazine flow rate of 0.3 $\mathrm{ml} / \mathrm{min}$, DCS/ Borazine ratio of $8.2 ; \mathrm{NH}_{3} /$ Borazine ratio of 4.6.

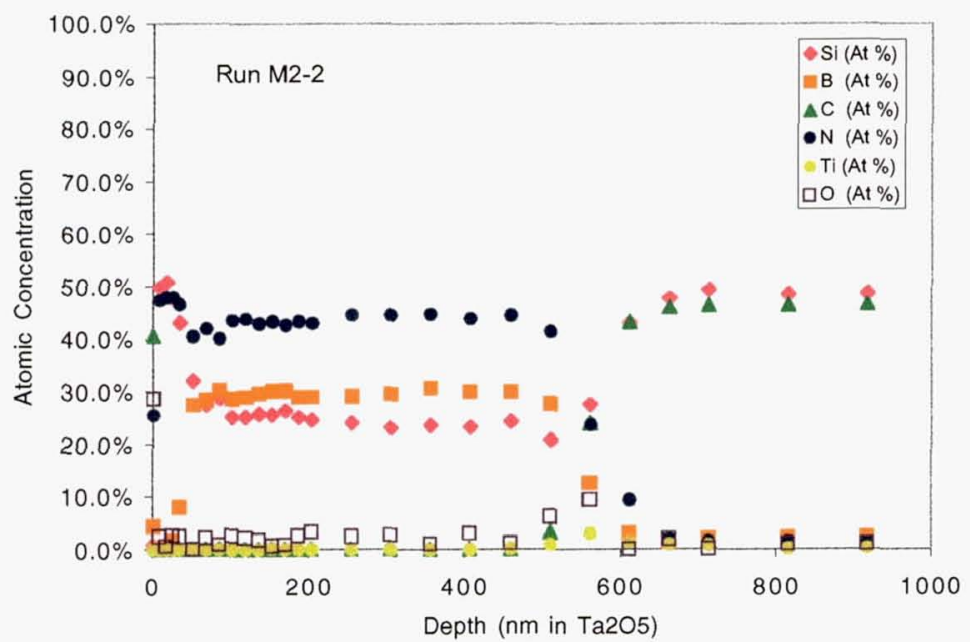

Figure 7. Auger depth profile of coating deposited at borazine flow rate of $0.6 \mathrm{ml} / \mathrm{min}, \mathrm{DCS} /$ borazine ratio of $32.8 ; \mathrm{NH}_{3} /$ Borazine ratio of 9.2 .

doped $\mathrm{BN}$ coatings of Matrix I. The concurrent flow of borazine and $\mathrm{NH}_{3}$ resulted in an increase in N/B ratio of $>1$, suggesting that $\mathrm{Si}-\mathrm{N}$ species are formed. 

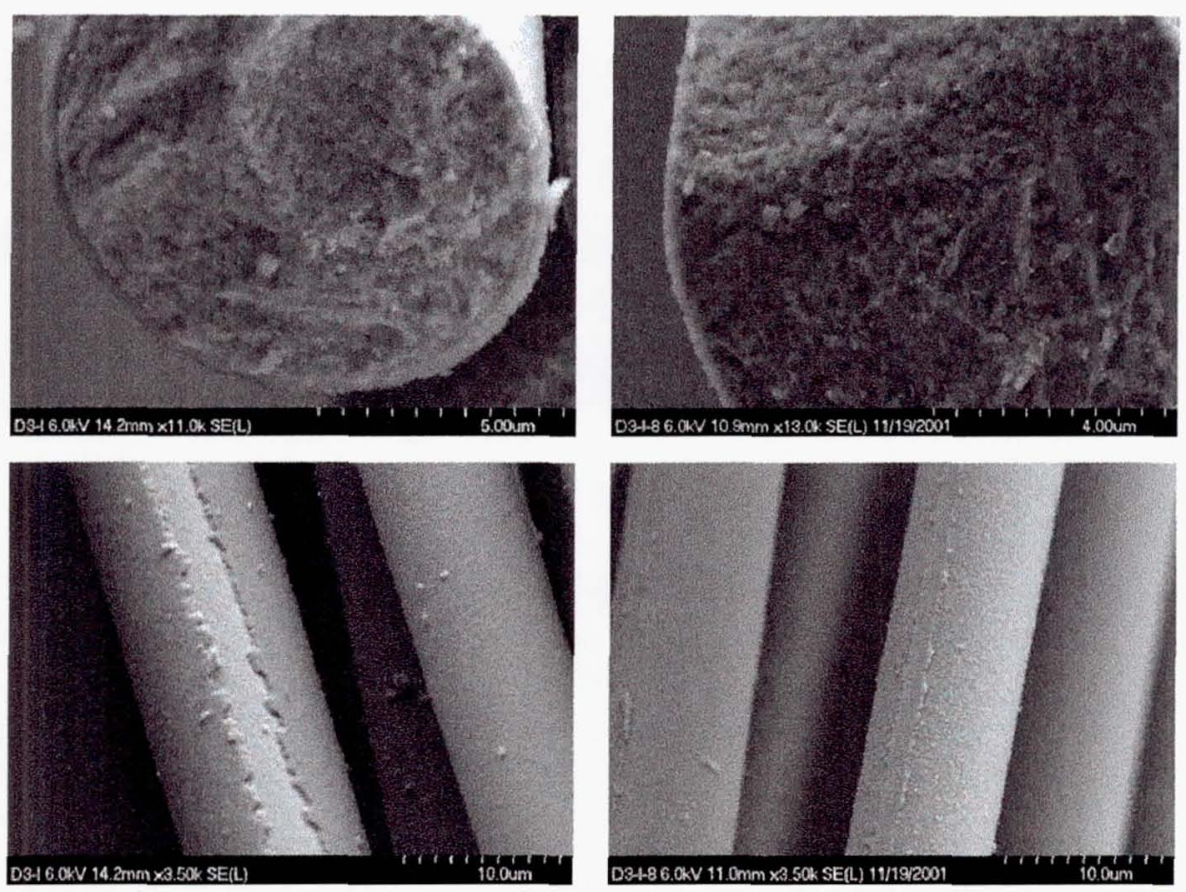

Figure 8. Coating on single fabric layer (left) and preform layer 8 (right), deposited at a borazine flow of $0.6 \mathrm{ml} / \mathrm{min}, \mathrm{DCS} /$ Borazine ratio of 2.1

Deposition of un-doped $\mathrm{BN}$ at $800^{\circ} \mathrm{C}$ into an eight ply Sylramic fabric perform, fixtured using graphite tooling, produced coatings which were uniform in thickness and composition throughout the eight plies, but which were extremely thin $(<100 \mathrm{~nm})$, even when $20015 \mathrm{sec}$ borazine cycles were used, as compared to the 100 cycles employed in the Matrix I coating runs. In preform coatings with DCS, the DCS/ Borazine ratio was reduced to 2.1, and the number of cycles to 100 , in an attempt to maintain thin coatings and more uniform infiltration. Infiltration and coating thickness were uniform through the eight plies, producing a coating of approximately $160 \mathrm{~nm}$, compared with a coating thickness of $230 \mathrm{~nm}$ on the single fabric layer included upstream from the perform in the same run (Fig. 8). Coating composition, as determined by EDS, is shown in Fig. 9. In a fabric layer from the preform the $\mathrm{Si}$ signal is from the fiber, as can be determined from the $\mathrm{Si} / \mathrm{C}$ peak ratio, while in the single fabric layer, the carbon peak is absent, and the Si peak arises from $\mathrm{Si}$ in the coating. The absence of $\mathrm{Si}$ within the perform layers was confirmed quantitatively by Auger depth profiling. The coating on the fabric downstream from the preform was highly non-uniform, nucleation may have occurred in the vapor phase rather than on the fiber surface (Fig. 10). This non-uniformity may be related to turbulence, as DCS flow had to be readjusted several times during the run. Lowering the deposition temperature to $700^{\circ} \mathrm{C}$ produced much thinner coatings (nominally $50 \mathrm{~nm}$ ), but $\mathrm{Si}$ was absent within the perform. Therefore perform infiltration remains to be optimized for $\mathrm{Si}$ incorporation. 

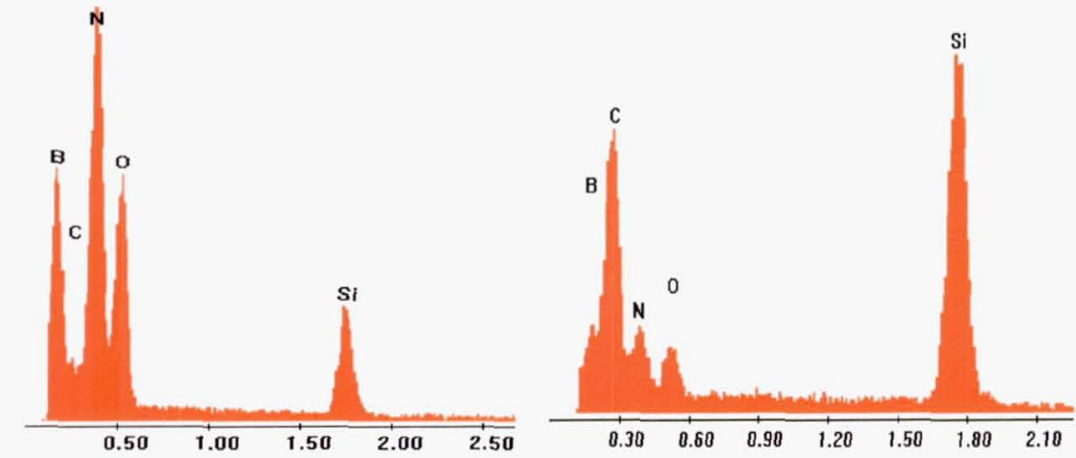

Figure 9. EDS spectra of coating on single fabric layer (left) and layer 8 of preform (right) from Run D3.

Figure 10. Coating on fabric downstream of preform, Run D3.

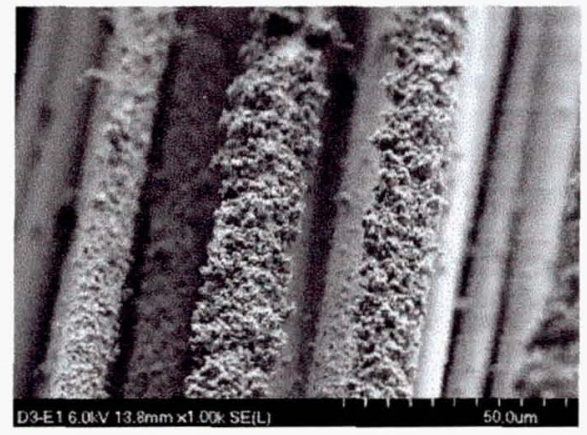

\section{SUMMARY AND CONCLUSIONS}

Substantially uniform BN coatings were deposited into Sylramic 5 HS cloth by pulsed CVI using a borazine precursor and liquid delivery system, and a relatively small CVI reactor. Optimal coating thickness, without fiber bridging and accompanying fabric embrittlement, was attained at a deposition temperature of $800^{\circ} \mathrm{C}$ and pressure of 25 torr. The $\mathrm{BN}$ coatings all contained oxygen and some carbon, and N/B ratios of $<1$. Addition of $\mathrm{Si}$ as a dopant from a DCS source enabled control of $\mathrm{Si}$ incorporation over a fairly wide range (6-24 atomic percent). Rather uniform, continuous SiBN coatings were deposited on single layers of fabric. Oxygen levels in the doped coatings were greatly reduced ( 2.5 atomic percent) as compared with the undoped BN (15-20 atomic percent). The deposition rate, and therefore coating thickness, was found to increase initially with increasing DCS/ borazine molar ratio, and then level off. Variation in timing and flow rate of $\mathrm{NH}_{3}$ during deposition enabled control of the N/B ratio.

Thinner BN coatings were deposited within eight-layer fabric performs held within graphite tooling. Si was not incorporated within the perform layers, though substantial Si was found on single fabric layers included within the same run, suggesting that DCS is rapidly depleted from the reactor atmosphere, The DCS/borazine ratio in the perform coating runs was 
lower than that used for single layer fabric, with the expectation that this would reduce the deposition rate and yield more uniform infiltration. Si incorporation might be improved using higher DCS rates or alternative Si sources.

Substantial advances were made during this program in the mechanics of using borazine in the CVI process, which will be of value to future efforts using borazine precursors. Several observations indicate that further study of pump options is required to assure that flow rates of borazine are well controlled at flows below $0.5 \mathrm{ml} / \mathrm{min}$. Future efforts should include understanding and controlling of $\mathrm{Si}$ incorporation within multiplayer performs, through investigation of alternative $\mathrm{Si}$ sources and relevant process variables. Use of $\mathrm{NH}_{3}$ flow parameters to control $\mathrm{B} / \mathrm{N}$ ratios also need to be investigated further. An experimental design with a larger number of runs is required to identify interactions between deposition parameters.

\section{REFERENCES}

1. Jacobson, N., et al., High-Temperature Oxidation of Boron Nitride: I, Monolithic Boron Nitride, J. Am. Ceram. Soc., 1999, 82(2): 393-98.

2. Jacobson, N.S., et al., High-Temperature Oxidation of Boron Nitride: II, Boron Nitride Layers in Composites, J. Am. Ceram. Soc., 1999, 82(6): 1473-82.

3. More, K.L., et al., Degradation Mechanisms of BN Interfaces in SiC/SiC Composites in Oxygen- and Water-Containing Environments, Proc. Electrochem. Soc., 1998, 98-9: 38292.

4. Morscher, G.N., D.R. Bryant, and R.E. Tressler, Environmental Durability of BN-Based Interphases (for $\mathrm{SiCf} / \mathrm{SiCm}$ Composites) in $\mathrm{H}_{2} \mathrm{O}$ Containing Atmospheres at Intermediate Temperatures, Ceram. Eng. Sci. Proc., 1997, 18(3): 525-34.

5. Sun, E.Y., H.-T. Lin, and J.J. Brennan, Intermediate-Temperature Environmental Effects on Boron Nitride-Coated Silicon Carbide-Fiber-Reinforced Glass-Ceramic Composites, J. Am. Ceram Soc., 1997, 80(3): 609-14.

6. Moore, A.W., et al., Improved Interface Coatings for SiC Fibers in Ceramic Composites, Ceram. Eng. Sci. Proc., 1995, 16(4): 409-416.

7. Phani, A.R., S. Roy, and V.J. Rao, Growth of Boron Nitride Thin Films by MetalOrganic Chemical Vapour Deposition, Thin Solid Films, 1995, 258: 21-25.

8. Maeda, M. and T. Makino, Low Dielectric Constant Amorphous SiBN Ternary Films Prepared by Plasma-Enhanced Deposition, Jap. J. Appl. Phys., 1987, 26(5): 660-665.

9. Hurwitz, F.I., P.V. Chayka, and J.M. Scott, Progress on BN and Doped BN Coatings on Woven Fabrics, Ceram. Sci. Eng. Proc., 2001, 22: 381-397. 